\title{
Building youth leadership confidence in 1475 (Dulwich) Squadron Air Training Corps: Handling challenges with no right answer and focusing on positives
}

Kevin Mehmet and Chris Howell

dulwichaircadets@yahoo.com, chrishowell001@gmail.com

\section{Abstract}

This article reflects upon the 1475 Dulwich Squadron Air Training Corps (ATC) Cadet Non-Commissioned Officer (NCO) training course. The course was first delivered in 1982 for fourteen- to seventeen-year-olds, running between November and April every year since then. The contemporary course consists of 210 hours of instruction, training, outbound exercises, in-class workshops, debriefing, individual feedback and coaching. The focus of this course is on communication, teamwork, emotional intelligence, confidence and courage. The young people are taken out of their comfort zones delivering talks, giving instruction to other cadets and taking turns in leadership during the challenging outbound exercises. The core philosophy of the course is to present the young people with complex problems where there is no right answer. Then the young people are debriefed, drawing out lessons that they have learnt themselves and using a positive constructive frame for the learning. This article explores our journey across various iterations of leadership courses to this contemporary course, why this work has been important, what worked, what didn't and how this work has positively changed the outcomes for cadets and the operation and practices of the 1475 Squadron, to deliver a strong young leadership team.

\section{Introduction}

The Air Training Corps (ATC) is a community-based program and is part of a UK-wide Air Cadet Organisation sponsored by the United Kingdom Royal Air Force (RAFAC 2016a). More than 40,000 young people aged between twelve and twenty years, of both sexes, participate in the Air Cadets (RAFAC 2016b). The Air Training Corps is made up of 930 Squadrons in diverse communities around the United Kingdom, and originally was created in 1941 to provide manpower for the 
Royal Air Force (RAFAC 2016b, 2016c). Today, one of its key aims is to encourage a spirit of adventure and to develop qualities of leadership and good citizenship (RAFAC 2016c).

The contemporary cadet journey involves a training syllabus containing both structured lessons and practical first-hand experiences (RAFAC 2016d). Set out in six progressive stages of skill and knowledge development from Junior Cadet through to Master Air Cadet, each stage builds on previously developed capabilities, specialist technical training and increased activity choice, providing for promotion through four cadet non-commissioned officer (NCO) leadership ranks, ranging from Corporal to Cadet Warrant Officer (RAFAC 2016e). While the ATC is a uniformed program, there are no charges for the uniform as this cost is covered by the Royal Air Force. Cadets do, however, pay a small subscription - usually a couple of pounds per week - to help cover running costs of the unit (RAFAC 2016f). Each unit takes responsibility for its own fundraising efforts to support some additional travel, outbound activities, and the purchase of musical instruments and sports equipment.

Cadet activities include camping, sports, parades and drill movements. There are annual camps on RAF bases. Cadets can also experience shooting, adventure training, first aid, nationally recognised vocational qualifications, air experience flights, air navigation training, pilot training, Duke of Edinburgh Award, community service, music training and many other activities (RAFAC 2016d, 2016g, 2016h).

1475 Squadron was founded on 12 June 1941 by the London Borough of Lewisham, and is now based in Dulwich, South East London (1475 Squadron 2016). Today the squadron has between 60 and 120 cadets, depending on the success of annual recruitment programs. The young people with whom we work come from a wide diversity of social, cultural and religious backgrounds. Recruitment activities are targeted primarily at local schools. Word of mouth is a key source of recruitment, and young people also join after seeing the cadets at community events or on television.

This article tells our story of developing the 1475 (Dulwich) Squadron Air Training Corps (ATC) Cadet Non-Commissioned Officer (NCO) training course. We tell both of our stories through the eyes of one author only, Kevin, with the story of the other author (Chris) included at points in the narrative where he was most involved. We explain the problem and success criteria for the course, the evolution of the course through the years, the challenges experienced and the achievements witnessed through these challenges.

This story and our journey illustrate all the principles of the Good Practice Framework (Seymour 2012), as a leadership development course with an inclusive ethos, where community service, interaction within social networks and working ethically are a big part of the squadron's activities. Among many other things, the squadron supports the local church with labour for bazaars, has raised awardwinning sums of money for the RAF's leading charity, and is involved annually in the London Lord Mayor's Show and the local community Remembrance Sunday parade where the squadron band leads the entire community. The NCO course graduation is at a formal black-tie dinner in central London with parents and invited VIPs, where the cadets demonstrate their training, confidence and social skills. 


\section{Kevin's story}

I joined 1475 Squadron in November 1972 aged fourteen, and I made my way up through all the cadet leadership ranks to reach Cadet Warrant Officer in 1978, aged twenty. I met Chris in 1973 when he also joined 1475 Squadron. His entire family was involved in the squadron at that time, and I worked alongside him as he progressed through the ranks to Flight Sergeant in 1978. As Cadet Warrant Officer and as Squadron 'Head-Boy', I was responsible for the NCO team. I applied to join the British Army as a commissioned officer, where I became aware of the highly specialised and comprehensive training modules that officer candidates receive. This experience, and my own experience as a cadet, inspired me to do further reading and research, resulting in me realising the importance of leadership skills and the need to offer leadership development to the cadets. I believed that cadets deserve opportunities to succeed, so I developed my vision that 1475 Squadron cadets would be empowered to get the job done and have the opportunity and benefits of leadership training. My application to join the army was unsuccessful on medical grounds (as I am blind in my right eye), so I stayed involved at the squadron through the years. I repeatedly saw cadets develop from students to effective young leaders and responsible professional people, citing the training they received on their NCO course as a measure of their success. This has been a most satisfying experience for me.

\section{Why I created the leadership course: The problem}

In the early 1970s, as young cadets, we both found expressing views up the chain of command in the squadron was considered inappropriate. In 1475 Squadron, we saw the process of promotion for a cadet to junior leader (Cadet Corporal) was to be noticed in some way by the commanding officer. Promotion was awarded for good service and conduct, and without true assessment of the individual's potential. Often the qualities noticed by the commanding officer were not the same as those experienced by other cadets or members of staff. The success of the junior leaders after promotion was therefore fairly random. Promotions were occasionally controversial - especially among those cadets who considered themselves worthy of promotion and did not receive it. Those promoted were not consistent in how they approached their duties and this had a negative effect on cadet morale.

\section{How the first leadership course worked}

The first NCO course that I introduced for the junior leaders was based on Dr John Adair's (1973) Action Centred Leadership. It targeted developing the skills and knowledge I thought were required to run the squadron effectively (1475 Squadron 1982). Training included learning how to take ownership of tasks, and how to inspire junior cadets to learn and give their best (1475 Squadron 1982). The tasks that required NCO leadership at this level included such activities as running the canteen, training a drill squad and teaching an academic lesson on, for example, the principles of flight.

I made sure that cadets would have the right to express a view on any matter under consideration until a decision was made, then it would be their duty to support that decision and do their utmost to carry it out. This change was important because I wanted the cadets to learn that two or more heads are better than one 
in decision-making, but that once a decision was made, they had to support the decision for the sake of team and squadron unity.

I also changed the promotion process. Now cadets were selected to go on the course and complete it using a continuous assessment process involving a threephase (one every six weeks) monitoring of their learning and progress. There were a number of qualifying final exams and practical assessments included in the new promotion process. Practical assessments involved such activities or tasks as acting as a duty NCO (leading on the logistics for an evening meeting), teaching, running small projects and leading drill training. These leadership development and assessment processes now provided a clear, measurable and relevant yardstick for promotion that everyone could understand and participate in. The NCOs were being trained to develop routines and take a consistent approach to their tasks.

\section{Initial success yet more problems and challenges}

The first course in November 1981 to April 1982 produced confident young people, yet was still a tick-box exercise. Cadets worked through checklists and this made me question the value of the leadership training. Through my interest in the armed services, I came across 'The Red Book' (Royal Military Academy 1960), which is used for British Army Officer Training at RMA Sandhurst and to inspire Officer Cadets of the Academy. It states that 'we must endeavour to produce at all levels commanders who inspire confidence in others'. While I could see that good developmental results, such as consistency, increased self-esteem and confidence, were being achieved, I realised that the NCOs were good at getting things done but not inspiring confidence in junior cadets. NCOs needed to mentor their juniors and were not doing so. When NCOs were making observations at debriefings, such as when cadets failed uniform inspection, their language was very negative: 'You did not do this ... Your shoes are not shiny ... You did not do that ...' To inspire confidence, we would need more positively focused language: 'Your shoes could be shinier, your trousers need to be pressed like this, your beret should be worn like this.' I wanted to apply the RMA motto 'Serve to Lead' (Royal Military Academy 1960) as the rock on which to build our leadership training, and I observed that this quality was not being demonstrated adequately after the training. I used the 'The Red Book' (Royal Military Academy 1960) as the basis for developing new lessons for the NCO course.

Chris had left the Squadron to study psychology at university, and subsequently progress his career. He maintained his contact with the squadron and shortly after I became 1475 Squadron's Commanding Officer in 1984, I invited Chris to take on the role of 1475 Squadron Chairman. We were both interested in developing the cadets' leadership skills, so I invited Chris to work with me on the next evolution of the course. In our conversations and reviews of the NCO course reports, Chris observed how the young people were describing their experiences of exercises and expressing their developing emotional awareness. From his experiences in working professionally with human resource professionals, Chris was aware that this language, and the way it reflected emotional intelligence, was increasingly being used as a tool for assessing potential employees and for developing future leaders. With the desire to increase ease of future employability as well as leadership, we remodelled the course, retaining the same syllabus yet placing a new focus 
on developing the young person's understanding of emotional intelligence. Chris trained the squadron adult staff involved in instructing on the course. Adult staff are normally recruited as ex-cadets of 1475 Squadron who wish to progress their careers, either as Squadron Civilian Instructors or commissioned officers. With the new course focus, cadets were debriefed on their experiences after every exercise, with coaching from the course instructors (1475 Squadron 1998, 2002). Debriefings were now much more personal, reflective and cadet centred, as cadets learnt to describe their experiences using language from the various intelligences (Golman 1995).

\section{What worked and what did not}

NCOs began to use this emotional intelligence language in speaking with each other and with the cadets. Their understanding of emotions, and how emotions relate to experience, raised self-awareness, focused on leadership with empathy and increased the cadets' resilience to emotional challenges. I could see that the problems of selection for promotion and leadership training were resolved by these curriculum changes. I could even see mentoring skills flourishing among the NCOs.

The next challenge to the leadership course was highlighted by the current 1475 Squadron President. 1475 Squadron has been honoured to have a serving Royal Air Force Air Marshal (a three-star ranking officer) as President; he has considerable operational experience. On one of his visits to 1475 Squadron, he highlighted an issue with some of the Practical Leadership Exercises. He pointed out that priority in the Practical Leadership Exercises had been given to achieving a desired objective and that this focus had led cadets, when working in a team, to make decisions that would not be acceptable in the real world, such as sacrificing an individual member for the sake of the end result.

In 2005, I therefore rewrote the course, placing a new focus on learning outcomes for team-working (group dynamics), courage, confidence and communication skills (1475 Squadron 2006). I introduced modular Practical Leadership Exercises and moved the learning priority onto the decision-making process rather than any specific result. The core philosophy of the contemporary course is to present the young people with complex problems where there is no right answer. The cadets are taken out of their comfort zones, delivering talks, giving instruction to other cadets and taking turns in leadership during the challenging outbound exercises. This contemporary course now consists of 210 hours of instruction, training, outbound exercises, in-class workshops, debriefing, individual feedback and coaching.

Each outbound exercise has been developed to challenge the team as a whole, test their decision-making and develop teamworking. As the cadets become used to working within their teams and draw strength from their peers, the exercises put them into situations where they are totally out of their comfort zones, and these experiences test their courage. The more their courage is tested in these team-based exercises, the more I see their confidence and their capacity to express themselves grow. Examples of the new Practical Leadership Exercises include: extracting information of a rendezvous from a contact who could not speak; negotiating the purchase of a stolen personal kit from bandits; and protecting and nurturing rare, delicate plants found on the mission by ensuring they are watered every 20 minutes while bringing the plants back to base. After these exercises, the young people are 
debriefed as a team. The debriefing is conducted by the team members themselves, facilitated by the instructor. Afterwards, in private, the cadets are debriefed individually by the course tutor. The debrief draws out lessons that they have learnt themselves using a positive constructive frame for the learning. Finally, they write a report of their experience to reinforce the learning. In its current form, I believe the Leadership Exercises are more representative of real-world situations and are better able to challenge the cadets to take ownership of their decision-making process as well as their emotions. The cadets are now better equipped to go into the world confident they can be effective leaders and team members, whether in the military or in a civilian environment.

\section{Conclusion}

We have seen how the development of the leadership course has had a profound impact on the culture, practices, operation and success of 1475 Squadron at every level. There are three specific changes following the work outlined in this article that we want to highlight here. First, NCOs meet regularly with the staff in open forum and any matters arising are discussed. NCOs are encouraged, as per their training, to speak out. This means that even junior leaders have a say and can influence the running of the squadron. The younger cadets can see and model the NCOs running the squadron. Second, the process of promotion is now consistent, objective and transparent, and from interviews and discussions with the cadets, NCOs can now be seen as role models who also provide inspiration to junior cadets. This means that third, and perhaps most importantly, the working environment within the 1475 Squadron has now changed to one that is convivial, respectful and constructive. Junior leaders can now carry out their duties without struggle, so we have an effectively run squadron that benefits everybody, giving cadets a sense of identity and of belonging to a successful team. They are then inspired to learn the tools of how to create and maintain a successful team themselves.

Our success in enriching the developmental outcomes for young people as they develop important life, practical and technical skills is represented in the skill and knowledge tests used throughout their leadership training. I am also witness to the anecdotal stories, told in the many letters of thanks I have received over the years from past and present cadets, about how participation in the 1475 Squadron changed their lives. The success of the squadron's work has also been recognised through the adoption and use of the course principles by the Air Cadets at London level, in other squadrons across the United Kingdom, and internationally by cadets in Hong Kong. An unexpected acknowledgement for the positive impact of these changes on cadet development came from the Commandant Air Cadets in 2011, when 1475 Squadron was awarded the Lees Trophy as the best squadron in the Air Training Corps. The letter of commendation made specific reference to the cadets' use of emotional intelligence language (Cooper 2010).

Perhaps the most significant evidence that we have changed practice successfully is that the NCOs exercise more responsibility in the running of the squadron than ever before. The NCO Course was designed to develop a strong NCO team, and has been successful in doing so. Course graduates continue to be responsible for organising and delivering the training program to the junior cadets in various roles from Cadet NCO rank of Corporal to the recently promoted adult 
Commanding Officer. The active delegation of the day-to-day running of more and more complex tasks to Cadet NCOs, within a supportive environment, delivers observable and measurable outcomes enabling them to demonstrate and build on their expertise. Parents are often amazed and very proud of the leadership of which their children are capable. A recent example saw a fifteen-year-old Cadet Sergeant putting a complex sequence of drill commands together for the change of squadron command parade in November 2015. This parade involved nearly 100 cadets performing in front of their parents, friends and guests of the squadron, including many dignitaries.

We are sure this leadership course, and the resulting changes to the culture, practices and operation of the 1475 Squadron, make a big difference to cadets' lives, giving them a significant positive start in understanding themselves, accepting responsibility, communicating leadership and inspiring confidence in others. We hope that by sharing this story, we are able to inspire other youth program leaders to further raise and fulfil the best aspirations of young people to inspire them to be brave to make changes - to be reflexive in their thinking and to constantly question whether they can do things better.

\section{Acknowledgements}

We acknowledge the support and inspirational encouragement of Dr Kathryn Seymour, Griffith University, in the writing of this article. We acknowledge HQ Royal Air Force Air Cadets UK for permissions.

\section{References}

1475 Squadron 1982. 'NCO course programme' (squadron working document unpublished).

1998. 'NCO course practical Leadership (command task) exercise management' (squadron working document - unpublished).

— 2002. NCO course (no. 18) leadership agility training (assessment): Operation order' (squadron working document - unpublished).

_ 2006. NCO course leadership training (assessment)' (squadron working document - unpublished)

— 2016. 'About us', http://www.1475.org/about-us/history.

Adair J. 1973. Action-centred leadership. New York: McGraw-Hill.

Cooper B. 2010. Letter to The Venerable (Air Vice-Marshal) R. Turner CB DL RAF Retd,

Goleman D. 1995. Emotional intelligence: Why it can matter more than IQ, London: Bloomsbury.

RAFAC 2016a. Royal Air Force Air Cadets home page, http://www.raf.mod.uk.

— 2016b. 'Who we are', http://www.raf.mod.uk/aircadets/whoweare.

— 2016c. 'History', http://www.raf.mod.uk/aircadets/whoweare/history.cfm.

— 2016d). 'What we do', http://www.raf.mod.uk/aircadets/whatwedo.

_ 2016e. 'Ranks', http://www.raf.mod.uk/aircadets/whoweare/ranks.cfm.

2016f. 'Frequently asked questions', https://www.raf.mod.uk/aircadets/wanttojoin/ cadets_faq.cfm. 
2016g. 'Training and education', http://www.raf.mod.uk/aircadets/whatwedo/ trainingandeducation.cfm.

— 2016h. 'Music', http://www.raf.mod.uk/aircadets/whatwedo/music.cfm.

Royal Military Academy 1960. Serve to lead: The British Army's anthology on leadership, 2nd ed. Sandhurst: Royal Military Academy.

Seymour K. 2012. Good practice principles for youth development organisations. 2nd ed. Brisbane: Key Centre for Ethics, Law, Justice and Governance, Griffith University. 